\title{
History of esophagectomy for cancer of the esophagus and the gastroesophageal junction
}

\author{
Toni Lerut ${ }^{1}$, Ory Wiesel ${ }^{2}$ \\ ${ }^{1}$ Surgery KULeuven, Department of Thoracic Surgery, University Hospital Gasthuisberg, Leuven, Belgium; ${ }^{2}$ Department of Surgery, Division of \\ Thoracic Surgery, Maimonides Medical Center, Brooklyn, NY, USA \\ Contributions: (I) Conception and design: Both authors; (II) Administrative support: None; (III) Provision of study materials or patients: None; \\ (IV) Collection and assembly of data: Both authors; (V) Data analysis and interpretation: None; (VI) Manuscript writing: Both authors; (VII) Final \\ approval of manuscript: Both authors. \\ Correspondence to: Toni Lerut, MD, PhD. Emeritus Professor of Surgery KULeuven, Emeritus Chairman, Department of Thoracic Surgery, \\ University Hospital Gasthuisberg, 3000 Leuven, Belgium. Email: toni.lerut@kuleuven.be.
}

\begin{abstract}
The introduction of anesthesia in 1846 created unseen opportunities for surgeons. By the end of the 19th century limited esophageal resection outside the chest had already been performed and the race for successful intrathoracic esophagectomy was on. The credit for the first successful esophagectomy for an intrathoracic cancer goes to Franz Torek of New York in 1913. But it was the introduction of double lumen intubation that really boosted the number of successful esophagectomies all over the world. In the second half of the 20th century progress in surgical techniques and perioperative management resulted in a substantial reduction of postoperative mortality. Introduction of multimodality therapies has further improved long term survival. The turn of the millennium saw the development of minimally invasive esophagectomy (MIE) improving postoperative quality of life. Undoubtly new technologies and newer drugs (e.g., immunotherapy) will further allow for refinements and more personalized targeted therapies. In this manuscript, the authors provide a deep dive into the history and development of esophageal surgery, with emphasis on the innovative pioneers that brought the field of esophageal surgery to the front line of surgery.
\end{abstract}

Keywords: Esophageal cancer; history; surgery; anesthesia

Submitted Feb 09, 2021. Accepted for publication Mar 19, 2021.

doi: $10.21037 / \mathrm{atm}-21-676$

View this article at: http://dx.doi.org/10.21037/atm-21-676

\section{In the beginning}

Cancer of the esophagus was described in China over 2,000 years ago.

Historical records dating from 2,000 years ago noted Ye Ge among the inhabitants of Henan (Henan) Province; Ye being the inability to swallow or having difficulty swallowing and Ge being an involuntary resistance to food and water after swallowing "Those discovered to suffer from esophageal cancer in the autumn", it was said, "will not live through the next summer".

The serious concern and fear of this disease in ancient times was reflected in the existence of the Houwang Miao, meaning "Throat God Temple." Unfortunately this temple was destroyed in 1927 (1).

In the second century Galen described "fleshy growths" as a cause of obstruction of the esophagus associated with cachexia and a fatal outcome (2).

In the 11th century Ibn Zuhr in the West known as Avenzoar (1091-1162), the leading authority of AraboIslamic medicine described the symptoms of esophageal cancer as "beginning with mild pain and difficulty in swallowing" and suggested the insertion of a long silver cannula into the esophagus for pouring liquids (3).

The first detailed description of anatomy of the digestive system and in particular the upper GI tract comes from Andreas Vesalius in his De Humani Corporis Fabrica in the fifth book published in 1543 (4). 
Jean Fernel (1497-1558) from France, one of the most outstanding medical figures of renaissance, in his De Morbis Universalibus et Particularibus, described the case of a woman who died in consequence of a large hard mass located in the esophagus (5).

The pathologist Théophile Bonet (1620-1689) from Paris recorded several cases of Esophageal growths which provoked obstruction, leading to death (6).

But as to any form of therapy it was waiting until the advent of anesthesia.

On October 16, 1846 ("Ether Day") William T. G. Morton a young dentist and surgeon John Collins Warren made anesthesia history at Massachusetts General Hospital in Boston with the successful use of diethyl ether "anesthesia" to prevent pain during surgery consisting in removing a tumor from the neck of Edward Gilbert Abbott. Warren asked the patient how he felt. Reportedly, Abbott said, "Feels as if my neck's been scratched." (7).

\section{Anesthesia: from negative to positive pressure}

Since this historic milestone, advancements in anesthesia administration and newer anesthetics led to the medical specialty of anesthesiology in the early 20th century. It is therefore worthwhile to describe the beginning as well as the remarkable progress made over time in thoracic anesthesia.

Vesalius studied medicine in Leuven, Belgium and is recognized as the father of Anatomy.

In his "De humanis Corpori Fabrica" he not only masterfully describes the anatomy but also comments on his findings on the collapse of the lungs when opening the chest of an animal in the last chapter of the Fabrica entitled "Some Observations in the Dissection of Living Animals", as follows:

"...But so that life may in some measure be restored to the animal, you must attempt an opening in the trunk of the trachea and pass into it a tube of rush or reed, and you must blow into this so that the lung may expand and the animal draw breath after a fashion; for at a light breath the lung in this living animal will swell to the size of the cavity of the thorax and the heart take strength afresh, and exhibit a variety of motions." (8). This is another brilliant example of Vesalius' genius. Here was the key to the future of thoracic surgery i.e., the principle of positive pressure ventilation. It is remarkable that Vesalius identified this but utilization of this was to lie dormant for 350 years!

Ferdinand Sauerbruch while working in Breslau in
1904, on request of von Mickulicz, developed an operating theater under negative pressure and thus exerted a negative pressure on the open chest in an attempt to overcome the deadly effect of opening the chest and resulting acute lung collapse and loss of cardio-respiratory function. The surgical team worked inside a chamber held at a pressure of -7 to $-8 \mathrm{mmHg}$ while the patient's head, and the anesthesiologist remained outside. By this means, he succeeded in maintaining respiratory function and, in 1904, was able to report its successful experimental use (9).

At the same time, his colleague Brauer in Marburg, tried the reverse method, the so-called positive pressure approach, whereby the patient's head was isolated in a positive-pressure chamber (10).

Meltzer and Auer in the US developed a device that made it possible to achieve insufflation of air or oxygen and ether in a continuous stream under low pressure $(15-20 \mathrm{mmHg}$ ), via a flexible silk woven catheter inserted through the mouth and larynx into the trachea. As a result, the lungs were kept in a state of normal distention, and the excess of expiratory air escaped through the trachea around the catheter. A footbellows was used to blow in the air at a constant rate (11). At the end of the 1920s, an inflatable cuff was added to the endotracheal tube by Guedel and Waters to improve ventilation and prevent aspiration (12). Shortly thereafter a technique of single lung ventilation was described by Gale and Waters (13). A major step forward was the introduction of double lumen intubation by Rowbotham and Magill from the UK in the twenties $(14,15)$. By 1940, principles and techniques had become relatively standardized consisting of intubating the contralateral lung and inflating the cuff at the level of the carina, causing collapse of the ipsilateral lung. In the late 1940s, Carlens in Sweden described a double lumen tube with unequal length and double cuff (16). Adaptations of these tracheal tube are still used now, in particular the lowpressure cuff introduced by Robertshaw (17).

Around the same era, curare was used as neuromuscular blocking drug, which made ventilatory control easier with lighter doses anesthetics. The polio epidemic marked the introduction of positive pressure ventilation in the early 1950 s and later in the 60's it was used for intraoperative mechanical ventilation in the thoracic surgery arena (18).

\section{Esophagectomy: from the first attempts to the first successful trans thoracic esophagectomy}

Together with the advancement of anesthesia, the renaissance of surgery had started. During the following 
Table 1 Pioneers in esophageal cancer surgery

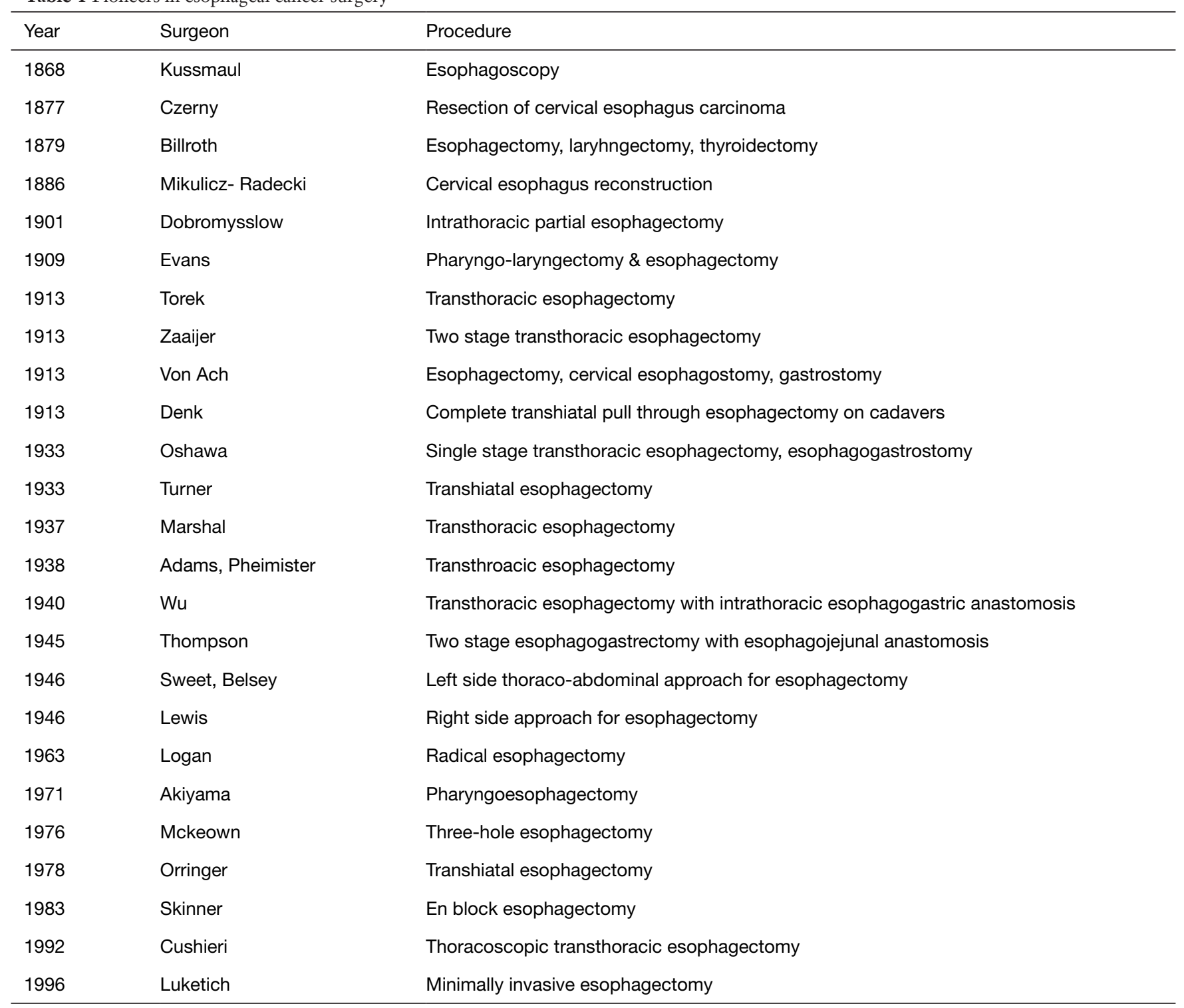

years, more and more surgical procedures were developed by skilled surgeons across the world (Table 1).

In 1868, Adolf Kussmaul (1822-1902) in Germany performed the first esophagoscopy He tested with success his device initially to a professional swordeater. It was a major contribution in the observation of the living esophagus and in diagnostics of esophageal pathologies, paving the way for new therapeutic approaches (19).

In 1877 one of the brightest assistants of Theodor Billroth (1829-1894), Vincenz Czerny (1842-1916), Kussmaul's son-in-law, resected a carcinoma of the cervical esophagus without restoring the continuity of the esophagus $(20,21)$.

Two years later in 1879 Billroth, father of modern European Surgery, himself resected a more extensive carcinoma, together with the larynx and thyroid gland, and a feeding esophageal tube was left in place.

Bougies were passed to maintain the lumen but unfortunately a bougie passed into the mediastinum and the patient died three days later from mediastinitis. With this technique nine resections by Billroth and other surgeons had been reported by 1885 , but only four patients survived (from 3 to 12 months) (22).

Jan Mickulicz-Radecki another famous pupil of 
Billroth and inventor of the esophagoscopy, successfully reconstructed the cervical esophagus by the use of skin flaps and the patient survived for 11 months (23).

By now the race to perform the world's first resection of the thoracic esophagus had started.

In the UK in 1909, Evans had performed the first excision of a cervical esophageal carcinoma using a pharyngo-laryngectomy and restored continuity to a gastrostomy with an external rubber tube.

The patient, Miss Alice Thomas, lived for 24 years until 1932 (24). She was the aunt of Tudor Edwards who performed the first successful trans pleural resection of the Torek type in the United Kingdom at the Westminster Hospital in 1935 (25).

Only one major obstacle had to be overcome: the deadly effect of opening the chest and resulting acute lung collapse and loss of cardio-respiratory function induced. Despite these difficulties further attempts were made to perform a transthoracic esophagectomy.

Meade, the thoracic surgical historian, described "the first successful intrathoracic resection and anastomosis of the esophagus" by Dobromysslow (1901). A 3- to 4-cm segment was resected, the ends united with two rows of silk sutures, and the anastomosis wrapped with a large posteriorly based skin flap. A complete union was seen at 3 weeks (26), But Meade reports that no further follow-up could be discovered (27).

The credit for the world's first successful transthoracic esophagectomy goes to Franz Torek in 1913 (28).

Torek was born in 1861 in Breslau Germany but moved to New York with his parents at the age of 11. On March 14, 1913, he operated a 67-year-old female patient at the German Hospital (now Lennox Hill) in New York, under general anesthesia administered by fellow surgeon Carl Eggers,

The patient had a squamous cell carcinoma of the middle third of the esophagus. After opening the chest the trachea was intubated with an ordinary rigid silk woven urinary catheter connected to a specially constructed Maltzer-Auer pump.

Torek writes "..... The tumor which passes behind the arch of the aorta offered great difficulties, which were finally overcome by dislodging the aorta at that site and lifting it forward after having ligated and divided a number of its thoracic branches..... The tumor was attached to the left bronchus which sustained a longitudinal cut during the progress of the separation of tumor from it. The cut in the bronchus was afterward sutured with silk...". Clearly a difficult operation!
After mobilization of the esophagus the tumor was resected and the distal part of the esophagus was ligated and invaginated. The proximal esophagus was brought out via a left cervicotomy and tunneled underneath the skin to create an esophagostomy at a level below the clavicula. A rubber tube connected the esophagostomy with a gastrostomy allowing oral feeding. The patient survived for 12 years eventually died from pneumonia.

At the 1913 meeting of the American Medical Association, Willy Meyer Torek's associate, presented a lengthy report of the first successful resection of the thoracic esophagus. To Meyer's surprise and disappointment, there was no discussion!

This indifference convinced him of the need for a special society in which thoracic surgical problems could be thoroughly discussed. In fact was the basis of the creation of the AATS in 1917. In 1925, Carl Eggers reported a second successful resection by Torek (29).

\section{Esophagectomy: from the first pioneers to minimally invasive esophagectomy (MIE)}

In 1913, Johannes Zaaijer in Leiden, the Netherlands, performed a successful staged trans-pleural resection of a carcinoma at the lower end of the esophagus, using the Sauerbruch negative pressure chamber to aid anesthesia. $\mathrm{He}$ brought the upper end of the esophagus on to the chest wall in the axilla (this had previously been mobilized by a 6th to 10th rib thoracoplasty to shorten the distance between the chest wall and esophageal bed). In a second stage a couple of days later he performed a distal esophagectomy and proximal gastrectomy. The stomach was pushed back in the abdomen and the remaining esophagus was sutured to the skin and connected to a feeding gastrostomy with a rubber tube. The patient died at day 17 from the complications a gastric leak (30).

In 1913, von Ach in Munich operated on a 55-year-old patient who presented with a distal third cancer. $\mathrm{He}$ mobilized the upper esophagus via a left cervicotomy and via a laparotomy the distal esophagus. After resection of the distal esophagus and proximal stomach he closed the distal esophagus and introduced via a cervical esophagostomy a steel rod down to the end of the esophagus. This steel rod had a "eye" opening in its distal end through which he could fix the esophagus with a thread passing through the esophageal wall and the eye of that rod and pulling it out via the cervical incision. The operation ended with a cervical esophagostomy and feeding gastrostomy. However, the 
patient died at day 17 (31).

In that same remarkable year 1913 Wolfgang Denk in Vienna performed on cadavers with carcinoma of the esophagus a complete transhiatal pull through using a combination of finger dissection around the tumor and a Mayo vein stripper but seemingly never used it on a patient (32).

In Japan, Oshawa from Kyoto in 1933 reported the first single stage transthoracic esophagectomy and esophagogastrostomy. He recorded since 1925, 16 cases of esophagectomy for carcinoma of the esophagus or gastric cardia, with an operative mortality of 50\% (33).

In the USA first Marshall from Boston in 1937 (34) and in 1938 Adams and Phemister from Chicago independently reported a transthoracic esophagogastrostomy (35).

In China, $\mathrm{Wu}$ working together with the American surgeon Loucks in Peking Union Medical Center performed at the age of 30 on April 26th 1940, the first transthoracic esophagectomy with intrathoracic esophagogastric anastomosis. In the same year 10, more resections were done with 3 early deaths (36).

In the UK, Thompson in 1945 in a first stage mobilized a jejunal loop brought up presternally under the skin. In a second step a trans-pleural esophagectomy was performed and the proximal esophagus anastomosed to the jejunum in the neck (37).

Grey Turner in the UK performed the first successful transhiatal esophagectomy on August 28th 1933. Through a high median abdominal incision, the distal part of the esophagus was mobilized by sharp and blunt finger dissection.

The proximal esophagus was dissected free via a cervical incision and transected distal to the tumor. The esophagus with the tumor was brought out via the cervical incision. Two months after the esophagectomy, gastrointestinal continuity was restored by a conduit constructed with an ante-thoracic skin flap and anastomosed to the jejunum in the neck (38).

Akiyama from Tokyo revived Gray Turners operation in 1971, applying it to patients with cancer of the hypopharynx. In 1975 he reported 25 patients without operative mortality (39). But it was Orringer in An Arbor, USA, who really popularized the transhiatal resection for cancer of the esophagus and gastroesophageal junction (40) after a memorable presentation at the AATS in 1978 in the discussion described by Belsey as an expedition into the Dark ages (41).

While the left sided approach as advocated by Sweet (42) and Belsey (43) with a modified version including a neck anastomosis. Ivor Lewis presented his work on the right sided two-phase approach for carcinoma of the middle third in 1946 (44).

McKeown from Darlington, UK, introduced three "hole" esophagectomy operation with anastomosis in the neck in 1976 (45).

Logan in Newcastle propagated the idea of a radical esophagectomy with an en bloc resection (46) later picked up by Skinner in Chicago (47). In Japan much attention was paid to extensive detailed 2- or 3-field lymphadenectomy, the third field being a bilateral neck lymph node dissection. Over time the postoperative mortality decreased substantially worldwide (48). A compilation of the world literature by Jamieson in 2004 showed post-operative of $8 \%$ and overall a five-year survival of $28 \%$ (49). As a result of better indication and in more recent years the introduction of multimodality, induction Chemo +/- Radiotherapy overall five-year survival has increased to figures between $30-40 \%$ including locally advanced stages and today 30 -day postoperative mortality is well below $5 \%$ in experienced centers

The credit for performing a thoracoscopic thoracic esophagectomy goes to Alfred Cuschieri from Dundee in 1992 (50).

But it is the merit of Jim Luketich from Pittsburgh to have developed and popularized the total MIE which is increasingly becoming the standard of surgical treatment all over the world (51).

\section{Back to the future}

New technologies, techniques and treatment modalities are emerging in an ongoing quest to improve results. Experience with robotic esophagectomy and uniportal VATS is growing reportedly reducing even more postoperative complications and related morbidity. Sentinel lymph node mapping and navigational techniques are tested hoping to avoid in the future the surgical trauma created by extensive lymphadenectomy in selected patients.

Treatment modalities aiming at preserving the esophagus such as EMR for early T1 cancers and definitive chemoradiation are already in place and in some centers definitive chemoradiation is the standard of care for advanced squamous cell carcinoma. These patients are closely monitored and in case of local recurrence salvage esophagectomy is offered as the last option in selected patients. 
These interventional endoscopic techniques are booming stimulated by the ever increasing miniaturization of instrumentation. The recent introduction of POEM challenging the classic laparoscopic Heller myotomy for achalasia is one perfect example of what can be expected in the future. One can easily imagine the application of this technology in cancer e.g., via myotomy entering the mediastinum for lymph node sampling.

Here the sky seems to be the limit, not to speak about the perspectives offered by the nanotechnology both in the area of diagnostics as well as in the therapeutic arena.

A wide spectrum of biologicals in the search for a more targeted therapy based on individual genetic profiles of the cancer are promising a tailored individualized treatment.

From all this it must become clear that there is a definite need for super-specialization in the field of esophageal pathology both benign and malignant.

The surgeon of tomorrow dealing with esophageal cancer will work in close collaboration with his/her peers in oncology, (interventional) radiology, interventional endoscopy...

This means that the different specialties as they are existing today will gradually grow towards each other eventually intertwining or merging. The result will be a complete re-engineering from surgery as a technical act into a unique form of therapy for each individual patient and for the better of the patient.

But this will require a strong engagement of from the surgeon to master the knowledge of esophageal cancer and to master the specifics of diagnosis and therapy (including complications and failure) of esophageal cancer.

\section{Acknowledgments}

Funding: None.

\section{Footnote}

Provenance and Peer Review: This article was commissioned by the editorial office, Annals of Translational Medicine for the series "Innovations and Updates in Esophageal Surgery". The article has undergone external peer review.

Conflicts of Interest: Both authors have completed the ICMJE uniform disclosure form (available at http://dx.doi. org/10.21037/atm-21-676). The series "Innovations and Updates in Esophageal Surgery" was commissioned by the editorial office without any funding or sponsorship. OW served as the unpaid Guest Editor of the series and serves as an unpaid editorial board member of Annals of Translational Medicine from Oct 2019 to Sep 2021. The authors have no other conflicts of interest to declare.

Ethical Statement: The authors are accountable for all aspects of the work in ensuring that questions related to the accuracy or integrity of any part of the work are appropriately investigated and resolved.

Open Access Statement: This is an Open Access article distributed in accordance with the Creative Commons Attribution-NonCommercial-NoDerivs 4.0 International License (CC BY-NC-ND 4.0), which permits the noncommercial replication and distribution of the article with the strict proviso that no changes or edits are made and the original work is properly cited (including links to both the formal publication through the relevant DOI and the license). See: https://creativecommons.org/licenses/by-nc-nd/4.0/.

\section{References}

1. Qian ZX. Investigation on esophageal cancer in the province of Xinjiang. Collected papers of the second symposium on esophageal carcinoma. Chinese Acad Med Sci 1961:74-8.

2. Kühn CG (Ed). De symptomatum causis. In: Claudii Galeni opera omnia. Tom VII pars L Leipzig, Knoblosh, 1824.

3. Karamanou M, Tsoucalas G, Saridaki Z, et al. Avenzoar's (1091-1162) clinical description of cancer. J BUON 2015;20:1171-4.

4. Andreas Vesalius. The Fabric of the Human Body. An annotated Translation of the 1543 and 1555 Editions of "De Humanic Corporis Fabrica Libri Septem". Book 5; Garrison DH, Hast MH Karger, vol 2:2014: pp 948 and 990

5. Fernel J. De Morbis Universalibus et Particularibus. libri IV posteriores pathologiae, 1645.

6. Bonet T. Sepulchretum sive anatomia practica. Geneva, Chouet, 1700.

7. Robinson DH, Toledo AH. Historical development of modern anesthesia. J Invest Surg 2012;25:141-9.

8. Earrington B. Vesalius A. The last chapter of the De Fabrica of Vesalius entitled some observations on the dissection of living animals. Latin Trans Roy Soc S Africa 1931:20;1-14.

9. Sauerbruch F. Zur Pathologie des offenen Pneumothorax und die Grundlagen meines-Verfahrens zu seiner Ausschaltung. Mitteil Grenzgeb Med Chir; 
1904:13:399-482.

10. Brauer L. Die Ausschaltung der Pneumothoraxfolgen mit Hilfe des Ueberdruckverfahrens. Mitteil. Grenzgeb. Med. Chir.; 1904:13;483-500.

11. Meltzer SJ, Auer J. Continuous respiration without respiratory movements. J Exp Med 1909;11:622-5.

12. Guedel AE, Waters RM. A new intra-tracheal catheter. Anesth Analg. 1928;7:238-9.

13. Gale J, Waters M. Closed endobronchial anaesthesia in thoracic surgery. J Thorac Surg 1932;1:432-7.

14. Rowbotham S. Laryngeal intubation in anesthetics. $\mathrm{Br}$ Med J 1923;1:1090-1.

15. Magill W. Endotracheal anesthesia Proc R Soc Med 1928;22:83-8.

16. Carlens E. A new flexible double-lumen catheter for bronchospirometry. J Thorac Surg 1949;18:742-6.

17. Robertshaw FL. Low resistance double-lumen endobronchial tubes. Br J Anaesth 1962;34:576-9.

18. Kacmarek RM. The Mechanical Ventilator: Past, Present, and Future Respiratory Care 2011;56:1170-80.

19. Kussmaul A. Zur geschichte der oesophago und gastroskopie. Arch Klin Med 1898;6:456.

20. Czerny V. Neue operationen. Zentralbl Chir 1877;4:433-4.

21. Karamanou M, Markatos K, Lymperi M, et al. A historical overview of laryngeal carcinoma and the first total laryngectomies. J BUON 2017;22:807-11.

22. Billroth CAT. Totalextirpation des Ganzenoesophagus vom Pharynx bis zum Sternum; ein Totalextirpation des Ganzenlarynx mit des ganzen Schilddruse. Verhandl Deut Ges Chir 1879;8:7-9.

23. Mikulicz J von. Ein Fall von Resektion des Carcinomatosen Oesophagus mit plastichen Ersatz des exeidirten Stuckes. Prag Med Wochenschr 1886;11:93-4.

24. Evans A. Rubber esophagus. Br J Surg 1932:20:388-92.

25. Edwards AT. Transpleural Removal of Total Thoracic OEsophagus. Proc R Soc Med 1935;29:188-90.

26. Dobromysslov WD. Ein Fall von transpleuraler Osophagotomie im Brustabschnitte. Zbl Chir 1901;1:18.

27. Meade R. A History of Thoracic Surgery. Springfield Illinois, USA: Charles C Thomas, 1961:662.

28. Torek F. The first successful resection of the thoracic portion of the esophagus for carcinoma. Surg Gyn Obstet 1913;16:614-7.

29. Eggers C. Resection of the thoracic portion of the esophagus for carcinoma. Arch Surg 1925:10:361-73.

30. Zaaijer JH. Erfolgreiche transpleurale Resektion eines Cardiacarcinomas. Beitr Klin Chir 1913;83:419-22.

31. von Ach A. Beiträge zur ösophagus-chirurgie [dissertation].
Munich, Germany: J.F. Lehmann's Verlag, 1913.

32. Denk W. Zur Radikaloperation des Oesophaguskarzinoms (vorläufige Mittelung). Zentralbl Chir 1913;40:1065-8.

33. Ohsawa T. Esophageal surgery. Nippon Geka Gakkai Zasshi 1933;34:1318-590.

34. Marshall SF. Carcinoma of the esophagus: successful resection of lower end of oesophagus with re-establishment of esophageal gastric continuity. Surg Clin North Am 1938;18:643-8.

35. Adams W, Phemister DB. Carcinoma of the lower thoracic esophagus. Report of a successful resection and esophagogastrostomy. J Thorac Surg 1938;7:621-7.

36. Wu YK, Loucks HH. Surgical treatment of carcinoma of the esophagus. Chin Med J 1941;60:1-33.

37. Thompson VC. Carcinoma of the oesophagus: resection and oesophago-gastrostomy. Br J Surg 1945;32:377-80.

38. Turner GG. Excision of the thoracic oesophagus for carcinoma with reconstruction of an extrathoracic gullet. Lancet 1933;ii;315-316-318.

39. Akiyama $H$, Tsurumaru M, Udagawa $H$, et al. Radical lymph node dissection for cancer of the thoracic esophagus. Ann Surg 1994;220:364-72.

40. Orringer MB, Sloan H. Esophagectomy without thoracotomy. J Thorac Cardiovasc Surg 1978;76:643-54.

41. Belsey RH. In discussion of paper by Orringer MB, Sloan H. Esophagectomy without thoracotomy. J Thorac Cardiothorac Surg 1978;76:654.

42. Sweet RH. Carcinoma of the esophagus and the cardiac end of the stomach immediate and late results of treatment by resection and primary esophagogastric anastomosis. J Am Med Assoc 1947;135:485-90.

43. Belsey RH. Surgical exposure of the esophagus. In: Skinner DBJ, Belsey RH. editors. Management of Esophageal Disorders. Philadelphia, London, Toronto, Montreal, Sydney, Tokyo: WB Saunders Company, 1988:192201,757 .

44. Lewis I. The surgical treatment of carcinoma of the oesophagus; with special reference to a new operation for growths of the middle third. Br J Surg 1946;34:18-31.

45. McKeown KC. Total three-stage oesophagectomy for cancer of the oesophagus. Br J Surg 1976;63:259-62.

46. Logan A. The surgical treatment of carcinoma of the esophagus and cardia. J Thorac Cardiovasc Surg 1963;46:150-61.

47. Skinner DB. En bloc resection for neoplasms of the esophagus and cardia. J Thorac Cardiovasc Surg 1983;85:59-71.

48. Akiyama H, Hiyama M, Miyazono H. Total esophageal 
reconstruction after extraction of the esophagus. Ann Surg 1975;182:547-52.

49. Jamieson GG, Mathew G, Ludemann R, et al. Postoperative mortality following oesophagectomy and problems in reporting its rate. Br J Surg 2004;91:943-7.

50. Cuschieri A, Shimi S, Banting S. Endoscopic

Cite this article as: Lerut $\mathrm{T}$, Wiesel O. History of esophagectomy for cancer of the esophagus and the gastroesophageal junction. Ann Transl Med 2021;9(10):897. doi: 10.21037/atm-21-676 oesophagectomy through a right thoracoscopic approach. J R Coll Surg Edinb 1992;37:7-11.

51. Luketich JD, Alvelo-Rivera M, Buenaventura PO, et al. Minimally invasive esophagectomy: outcomes in 222 patients. Ann Surg 2003;238:486-94. 